\title{
SASKATCHEWAN CHRISTMAS MAMMAL COUNT - 1980
}

Compiled by WAYNE C. HARRIS, Box 93, Raymore, Saskatchewan SOA 3J0

A total of 45 counts were submitted this year, recording 28 species during the count period. The number of counts is a record high and the number of species ties the high set in 1978.

The lack of snow in some localities resulted in a reduction in number of species from these areas, while in other areas the limited snow meant easier access and probably better counts than usual.

Population trends of most species were stable. Red Fox numbers were lower than usual although similar to last year. Coyotes were also slightly down. Snowshoe Hare numbers were similar to last year but White-tailed Jack Rabbits appeared to be down slightly. Pronghorn Antelope were also lower than usual. The unseasonably warm weather and lack of snow probably accounted for the presence of ground squirrels at
Spring Valley and Eastend.

Some of the highlights of this year's count included a Raccoon and Fox Squirrel from Regina, a pack of ten Timber Wolves feeding at a kill site in Prince Albert National Park and over 90 Elk at Fort Walsh in the Cypress Hills.

For weather, coverage and participants of these counts please refer to the Christmas Bird Counts found elsewhere in this issue. Symbols found in the Table are as follows:

* Identified by tracks with the estimated number of animals in parentheses.

+ Seen during count period but not on count day.

$L$ Active lodges seen with the number in parentheses.

D Freshly dead animals found with the number in parentheses.

$H$ Species heard but not seen with number in parentheses.

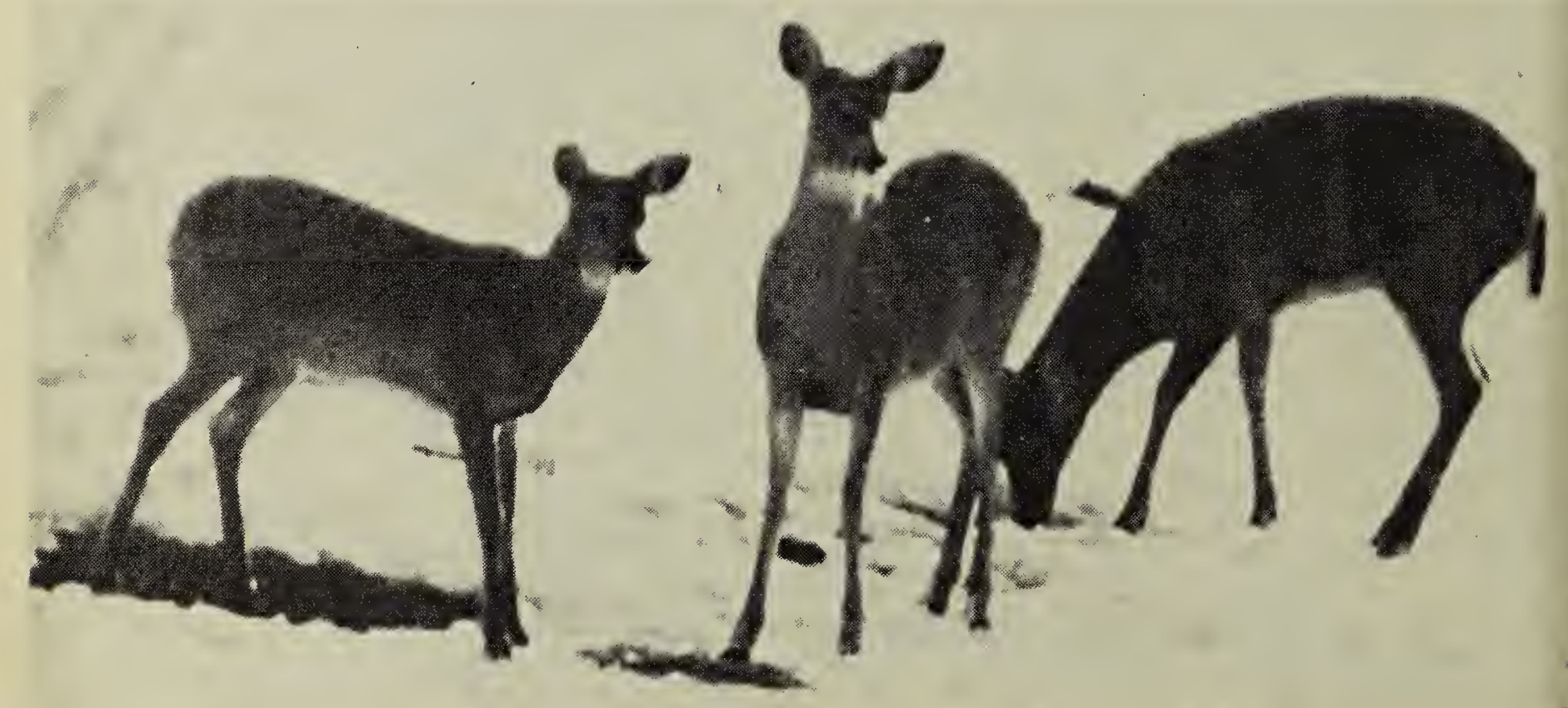




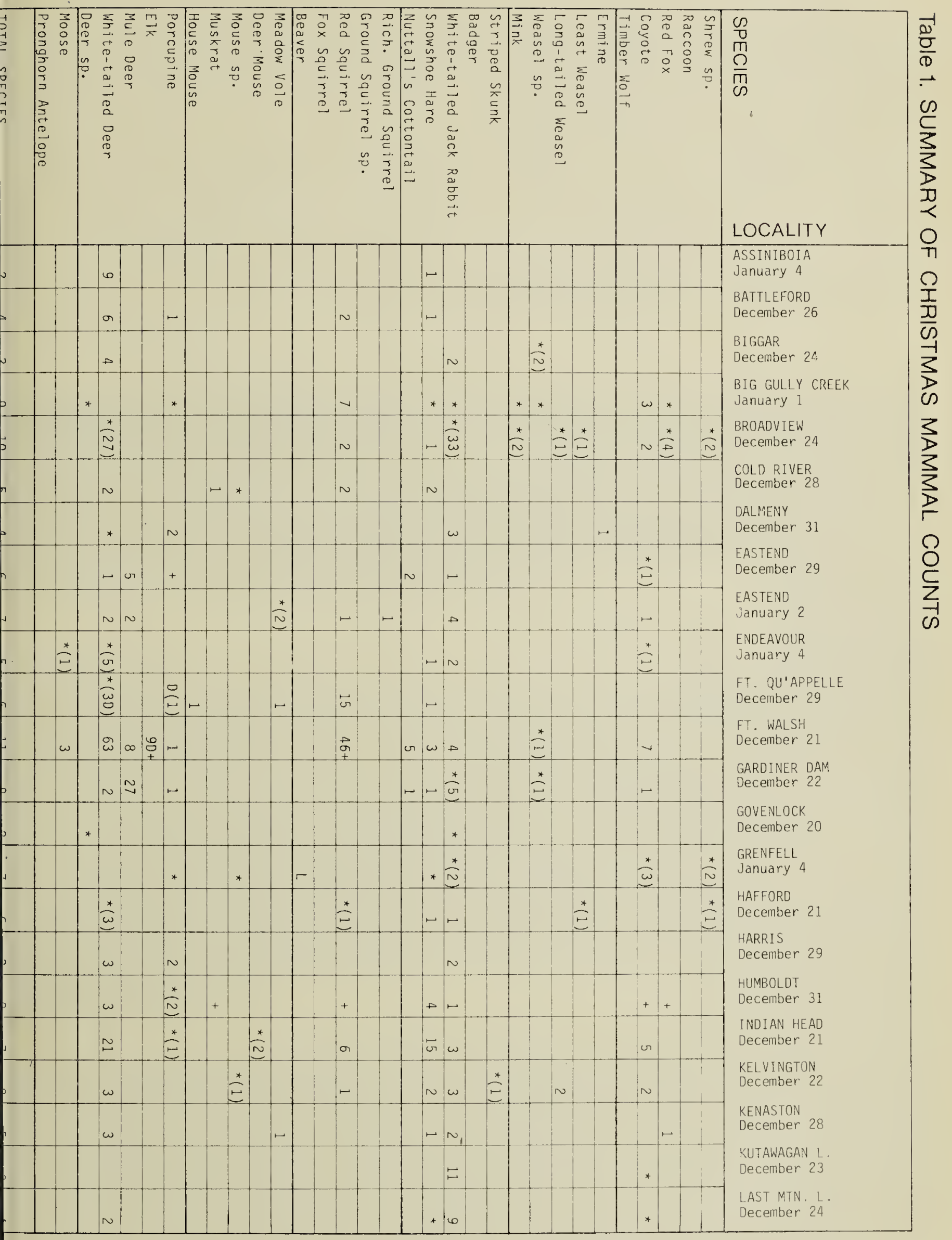




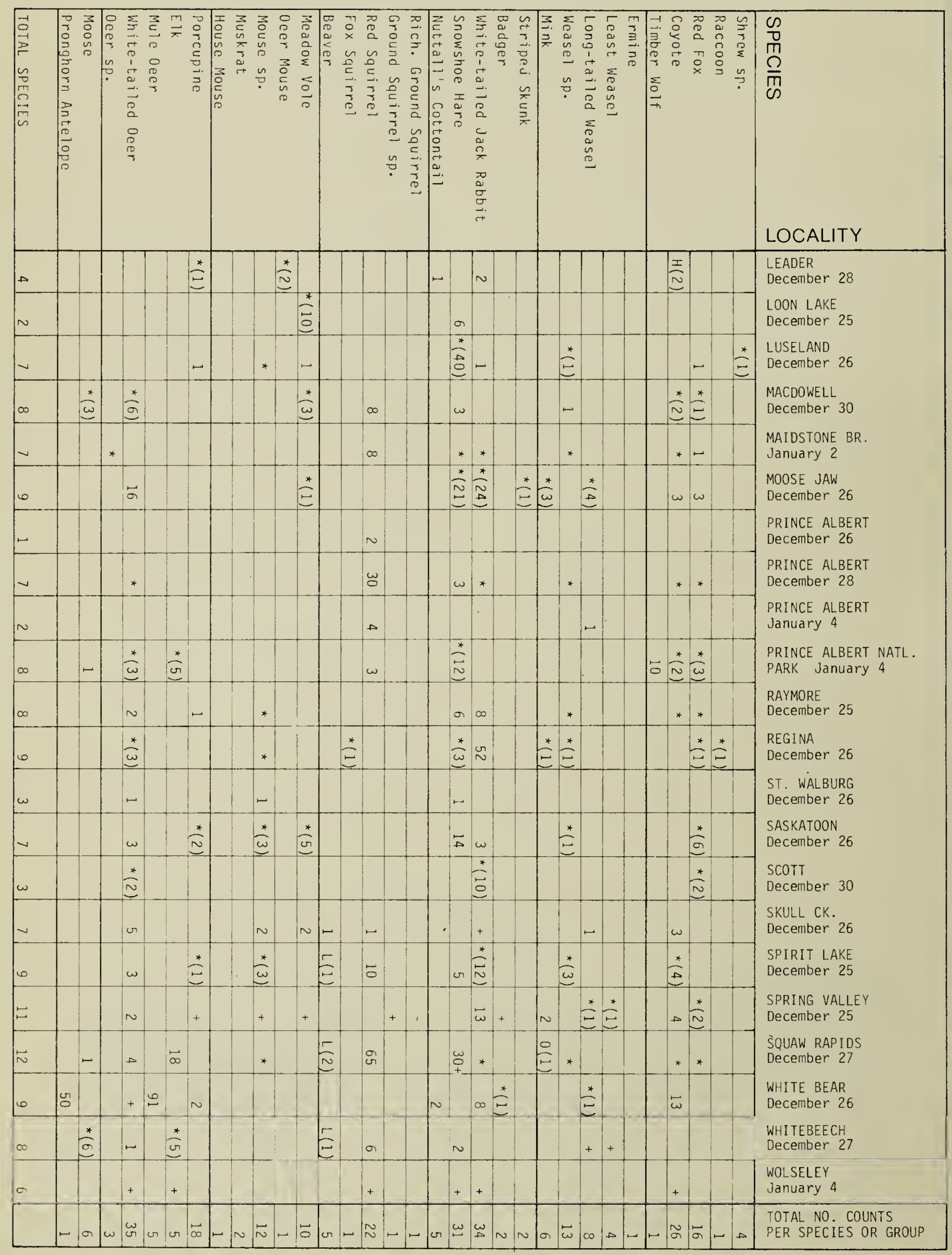


